\title{
Vitamin D deficiency in schizophrenia implications for COVID-19 infection
}

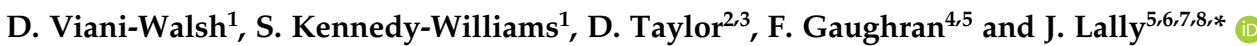 \\ ${ }^{1}$ Graduate Entry Medicine, Royal College of Surgeons in Ireland, Dublin, Ireland \\ ${ }^{2}$ Director of Pharmacy and Pathology, South London and Maudsley NHS Foundation Trust, London, UK \\ ${ }^{3}$ King's College London, Institute of Psychiatry, Psychology and Neuroscience, London, UK \\ ${ }^{4}$ National Psychosis Service, South London and Maudsley NHS Foundation Trust, London, UK \\ ${ }^{5}$ Department of Psychosis Studies, Institute of Psychiatry, Psychology and Neuroscience, London, UK \\ ${ }^{6}$ Department of Psychiatry, Royal College of Surgeons in Ireland, Dublin, Ireland \\ ${ }^{7}$ St Vincent's Hospital Fairview, Dublin, Ireland \\ ${ }^{8}$ Department of Psychiatry, Mater Misericordiae University Hospital, Dublin, Ireland
}

\begin{abstract}
Vitamin D deficiency is associated with an increased risk of acute respiratory infection. There is an excess of respiratory infections and deaths in schizophrenia, a condition where vitamin $D$ deficiency is especially prevalent. This potentially offers a modifiable risk factor to reduce the risk for and the severity of respiratory infection in people with schizophrenia, although there is as yet no evidence regarding the risk of COVID-19. In this narrative review, we describe the prevalence of vitamin D deficiency in schizophrenia, report the research examining the relationship between vitamin D levels and COVID-19 and discuss the associations between vitamin D deficiency and respiratory infection, including its immunomodulatory mechanism of action.
\end{abstract}

Received 16 May 2020; Revised 28 July 2020; Accepted 04 September 2020; First published online 11 September 2020

Key words: $25(\mathrm{OH}) \mathrm{D}$, antipsychotics, immune, pneumonia, psychosis.

\section{Introduction}

In December 2019, a novel coronavirus, severe acute respiratory syndrome coronavirus 2 (SARS-CoV-2), emerged in Wuhan, Hubei province, China. The World Health Organization (WHO) declared coronavirus disease 2019 (COVID-19) a pandemic on 11 March 2020. While it is estimated that $80 \%$ of those with COVID-19 are asymptomatic or have a self-limiting disease, the case fatality rate for those hospitalised with COVID-19 is $2.3 \%$, increasing to $10.5 \%$ in those with cardiovascular disease, $7.3 \%$ in those with diabetes mellitus and $6 \%$ in those with hypertension $(\mathrm{Wu} \&$ McGoogan, 2020).

People with schizophrenia have an excess of physical co-morbidities and reduced life expectancy (Hjorthøj et al. 2017), and may be an especially vulnerable group to COVID-19 disease and increased mortality (Kozloff et al. 2020). Patients with schizophrenia have a higher burden of the risk factors identified above (Gardner-Sood et al. 2015; Gaughran et al. 2019; Lally, Spaducci, et al. 2019), leaving them more vulnerable to adverse outcomes of infection. There is also an excess

*Address for correspondence: Dr J. Lally, PO63, Department of Psychosis Studies, Institute of Psychiatry, Psychology and Neuroscience (IoPPN), King's College London, De Crespigny Park, London SE5 8AF, UK.

(Email: john.lally@kcl.ac.uk) of deaths from pneumonia and influenza in people with schizophrenia (Olfson et al. 2015a). Exploring possible protective factors to mitigate risk, therefore, is essential for this vulnerable patient group.

Vitamin D is known to have a critical role in the immune system, influencing many functions of the normal immune response to pathogens. In those who are vitamin D deficient, immune function is disrupted in favour of a pro-inflammatory state. Dysregulated inflammation and 'cytokine storms' are associated with worse outcomes in COVID-19, contributing to the severity of acute respiratory distress syndrome (ARDS) and organ dysfunction (Cao, 2020). Early data currently available only as preprints suggest a major effect for vitamin D status on COVID-19 outcome (Alipio, 2020; Raharursan, 2020). The prevalence of vitamin D deficiency in schizophrenia is high, therefore, one potential stratagem to mitigate the risk of COVID-19 in schizophrenia may be to optimise vitamin D concentrations. This study reviews the association between vitamin D deficiency and the risk of infection and provides suggestions for optimising vitamin D in people with schizophrenia.

\section{Background}

The two main forms of vitamin D are vitamin D3, or cholecalciferol, which is formed in the skin after exposure to sunlight (ultraviolet B (UVB) radiation) 
Table 1. Classification of vitamin D status for skeletal health

For the ranges below, vitamin $\mathrm{D}$ status is measured in terms of $25(\mathrm{OH}) \mathrm{D}$ serum concentration

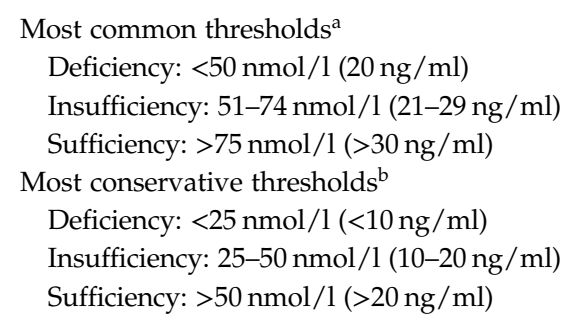

a Holick \& Chen (2008); US Institute of Medicine: Ross et al. (2011).

${ }^{\mathrm{b}}$ International Osteoporosis Foundation: Dawson-Hughes et al. (2010).

and ergocalciferol, or vitamin D2, which is obtained by UV irradiation of plants or plant sources. Vitamin D has a central role in bone mineralisation and its primary function is to aid the intestinal absorption of calcium and phosphate (Holick, 2012).

There is long-standing evidence linking vitamin D deficiency with skeletal disease, including rickets (Holick, 2006), osteomalacia, muscle weakness (Redzicet al. 2013), falls, osteoporosis and fractures (Redzic et al. 2013; Bolland et al. 2018) (Table 1). Increasing observational and epidemiological data have identified associations between vitamin D deficiency and non-skeletal diseases, including infectious diseases (Bouillon et al. 2019).

Ecological evidence is suggestive of links between seasonal vitamin $\mathrm{D}$ deficiency and increased respiratory infection risk (Grant, 2008). Further, preliminary epidemiological data points to increased mortality rates from COVID-19 in populations living above latitude $35^{\circ}$ North, compared to those in countries below $35^{\circ}$ North, this coincides with those countries in which vitamin D deficiency is more prevalent due to inadequate sunlight exposure in Winter months (Rhodes et al. 2020). In this narrative review, we will describe the prevalence of vitamin D deficiency in the first episode and established psychosis, and the associations between suboptimal vitamin D and respiratory tract infections. We will provide an analysis of the potential benefits of vitamin D supplementation as a preventative measure for those with schizophrenia at risk of vitamin $\mathrm{D}$ deficiency associated respiratory infection and COVID-19.

\section{Prevalence of vitamin D deficiency in schizophrenia}

People with schizophrenia and other psychotic disorders are at high risk for vitamin D deficiency. A crosssectional study of community-based patients in the UK identified that $90 \%$ of people with established psychosis had suboptimal levels of vitamin D $(<20 \mathrm{ng} / \mathrm{ml}$
$(<50 \mathrm{nmol} / 1))$, with a vitamin D deficiency $(<10 \mathrm{ng} / \mathrm{ml}$ $(<25 \mathrm{nmol} / \mathrm{l}))$ rate of $50 \%$, much higher than the rate of $15 \%$ rate in the UK general population (Ruston et al. 2004). Rates of vitamin D deficiency of $49 \%$ were identified in the UK hospital population of patients with schizophrenia (Patel \& Minajagi 2018). Comparable vitamin $\mathrm{D}$ deficiency rates have been identified in the first-episode psychosis (Lally, Ajnakina, et al. 2019), with the risk of vitamin $\mathrm{D}$ deficiency in individuals with FEP being threefold higher than in their age, gender and ethnicity-matched controls (Crews et al. 2013). Consequences of low vitamin D, including the relationship with infection risk in this population are unclear as of yet and require further research.

\section{Vitamin D and respiratory infection risk}

There is an inverse relationship between serum vitamin $\mathrm{D}$ concentrations and the risk of acute respiratory tract infections (Martineau et al. 2017). A recent metaanalysis of eight observational studies $(n=21000)$ identified that individuals with a vitamin D level $<20 \mathrm{ng} / \mathrm{ml}$ (i.e. $<50 \mathrm{nmol} / 1$ ) had a $64 \%$ increased risk of community-acquired pneumonia (Zhou et al. 2019).

There is evidence that vitamin D supplementation improves immune function and reduces the risk of respiratory infection, with higher vitamin D levels reducing the severity of influenza and respiratory infections(Grant \& Giovannucci, 2009; Martineau et al. 2017, 2019; Gruber-Bzura, 2018; Huang et al. 2020). A meta-analysis of individual participant data from 25 randomised controlled trials, reporting on 10933 participants, found that vitamin D supplementation was well tolerated and provided modest protection against acute respiratory tract infections (adjusted OR 0.88; 95\% confidence interval (CI) 0.81-0.96) (Martineau et al. 2017). The effects of vitamin D supplementation are more significant in those with vitamin D deficiency, with vitamin D supplementation reducing the risk of acute respiratory infection (Martineau et al. 2017). This is relevant to people with schizophrenia, the majority of whom have suboptimal vitamin $\mathrm{D}$ concentrations. This raises the possibility that vitamin $\mathrm{D}$ supplementation may not only provide skeletal benefits, but may contribute to protection against and reduction in the severity of respiratory infections, which may extend to SARS-CoV2.

\section{Mechanism}

Observational studies have identified associations between suboptimal vitamin D levels and increased respiratory infection risk, including SARs-CoV2 infection (Alipio, 2020; Lau et al. 2020), but do not 
attribute causation. There is, however, pre-clinical data providing mechanistic evidence of how vitamin D impacts on risk for viral infections (Grant et al. 2020).

\section{Vitamin $D$ function in the normal immune response}

The availably of adequate serum concentration of $25(\mathrm{OH}) \mathrm{D}$ is important in mounting an immune response and enhancing immunomodulation, while the absence of adequate vitamin D may lead to an aberrant response to pathogens or autoimmunity (Lang et al. 2013). The majority of immune cells express vitamin D receptor (VDR), and vitamin D has a role in immunomodulation, influencing antigen presentation, innate immunity and T-cell function (Lang \& Aspinall, 2017). Vitamin D also affects the expression of angiotensin-converting enzyme 2 (ACE2), the functional receptor of which has been identified as the entry site for the SARS-CoV-2 (Lu et al. 2020; Walls et al. 2020).

Activated vitamin D (1,25-dihydroxyvitamin D $\left.\left(1,25(\mathrm{OH})_{2} \mathrm{D}\right)\right)$ has a role in both innate and adaptive immunity. Macrophages and dendritic cells express VDR, and their function is responsive to circulating activated vitamin D (Chun et al. 2014). In response to a pathogen challenge, macrophages express increased VDR and $1 \alpha$-hydroxylase (CYP27B1), which then converts biologically inert vitamin $\mathrm{D}$ into its active form. The binding of VDR also inhibits the production of pro-inflammatory cytokines (Lang \& Aspinall, 2017). Vitamin D has been shown to inhibit the development of pro-inflammatory Th17 cells and initiate the expression of regulatory $\mathrm{T}$ cells that suppress inflammation and defend against autoimmunity (Lang et al. 2013; Ghavideldarestani et al. 2020).

\section{Vitamin D regulating inflammation}

Vitamin D is proposed to have anti-inflammatory effects. Vitamin D supplementation is associated with a reduction in C-reactive protein (CRP) in the general population (Chen et al. 2014), while in schizophrenia, an inverse relationship between vitamin D and CRP levels was identified (Lally et al. 2016). An unblinded RCT of vitamin D supplementation with $50000 \mathrm{IU}$ vitamin D3 (combined with probiotic supplements) in people with chronic schizophrenia demonstrated reductions in CRP and enhanced total antioxidant capacity compared to placebo (Ghaderi et al. 2019). Thus, vitamin D's suggested anti-inflammatory effects may have a protective role against the severity of acute respiratory infection in COVID-19.

An animal model study identified the beneficial effects of calcitriol, the biologically active form of vitamin D, in lipopolysccacaride (LPS)-induced lung injury. LPS is a glycoprotein with potent proinflammatory effects, inducing a strong inflammatory state and specifically damaging pulmonary vascular endothelial cells, resulting in acute lung injury and ARDS (Xu et al. 2017). The mechanism by which calcitriol produced these beneficial effects was via manipulation of the renin-angiotensin system (RAS), balancing the opposing effects of ACE and ACE2 in favour of low endovascular permeability.

Optimising serum $25(\mathrm{OH}) \mathrm{D}$ concentration is associated with responsive downregulation via induction of regulatory $\mathrm{T}$ cells and regulation of cathelicidinencoding gene expression (Lang \& Aspinall, 2017; Cao, 2020; Mccartney \& Byrne, 2020). Cathelicidins are stimulated by infection to produce powerful cytokines including IL-1, IL-6 and INF-gamma, vitamin D has a role in regulating this pro-inflammatory process (Lang \& Aspinall, 2017). The immunomodulatory effect of vitamin D could, therefore, attenuate some of the downstream inflammatory sequelae associated with poor clinical outcomes in severe respiratory illnesses including COVID-19 infection. These include persistent IL-6 elevation and prolonged interferon-gamma (INF $\gamma$ ) response as well as high levels of other pro-inflammatory cytokines, a state termed "cytokine storm" (Cao, 2020).

\section{Vitamin D and COVID-19 host cell invasion}

The ACE 2 receptor has been identified as the primary site for host cell invasion for COVID-19. ACE 2 is expressed in the airway epithelia and lung parenchyma, as well as digestive system organs. ACE 2 converts angiotensin II (Ang II) into angiotensin 1-7, which acts as a vasodilator with a regulatory role in the RAS. Vitamin D may suppress RAS activity via inhibition of renin and the ACE/Ang II/AT1R cascade (Ghavideldarestani et al. 2020). In the absence of adequate $25(\mathrm{OH}) \mathrm{D}$ serum concentration, this function can become less efficient, potentially contributing to effects such as increased inflammation and thrombotic events (Xu et al. 2017).

In Middle Eastern Respiratory Syndrome (MERS) 2, a molecular virulence mechanism including dipeptidyl peptidase-4 receptor (DPP-4/CD26) binding was identified. While the DPP-4/CD26 receptor has not been confirmed as a target for COVID-19, the genetic similarity of MERS 2 and COVID-19 (Walls et al. 2020), justifies considering this receptor a putative secondary adhesion molecule for COVID-19 host cell invasion (Mccartney \& Byrne, 2020). In pre-clinical models, correction of vitamin $\mathrm{D}$ deficiency is associated with reduced DPP-4/CD26 receptor expression(Komolmit et al. 2017).

\section{Summary}

The mechanisms by which vitamin $\mathrm{D}$ exerts its role in the immune system are multifactorial (Fig. 1). Low serum vitamin D concentration seems to be associated 


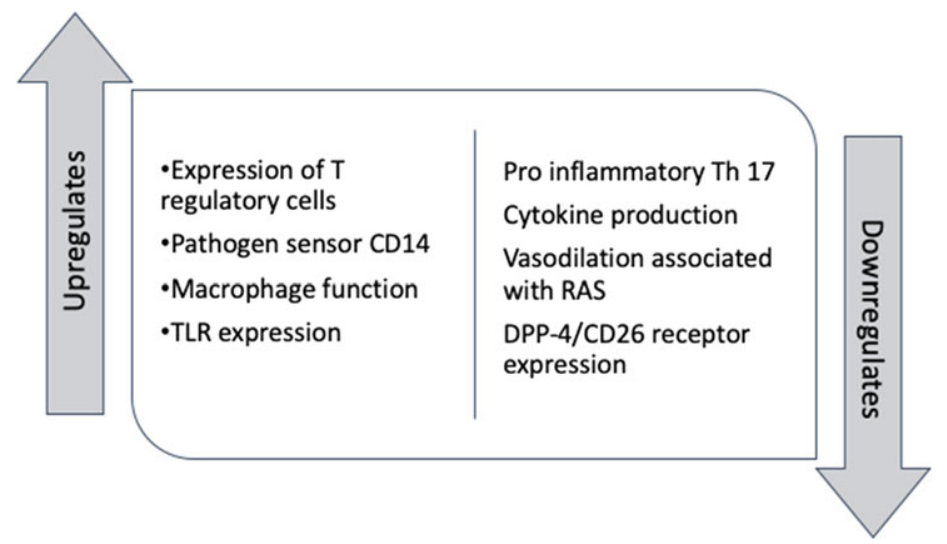

Fig. 1. Mechanism of vitamin D anti-inflammatory and immunomodulatory function.

with inhibition of normal immunomodulatory function in favour of pro-inflammatory state. Inadequate vitamin D levels may result in less efficient macrophage function and antigen presentation. Low vitamin D may, therefore, potentially contribute to a delayed or dysregulated response to the body's initial contact with SARS-CoV-2 or impede the mounting of an appropriate defence in established SARS-CoV-2 infection.

\section{Vitamin D optimisation strategies}

Vitamin D is mainly acquired from sunlight exposure, with a smaller amount gained from dietary sources (approximately 10\%). Although there is variation in the definition of vitamin D deficiency (Table 1), in Ireland, approximately $50 \%$ of both older ( $>55$ years) and adult age populations have vitamin $D$ insufficiency $(<50 \mathrm{nmol} / \mathrm{l})$ (Laird \& Anne Kenny 2020) and people with schizophrenia are a high-risk group for vitamin D deficiency (see Table 2).

The current recommendation for the prevention of vitamin D deficiency in adults in Ireland is daily vitamin D3 supplementation of $5 \mu \mathrm{g}$ (200 IU) and 10-15 $\mu \mathrm{g}$ (400-600 IU/day) for the high-risk groups according to healthy eating guidelines set out by the Food Safety Authority of Ireland (Food Safety Authority of Ireland, 2011). There is a differential dose response to vitamin D, with lower doses such as 400-600 IU/day more suited to prevent vitamin $\mathrm{D}$ deficiency, while higher doses are required to treat vitamin $\mathrm{D}$ deficiency.

Significant variations have been noted in the doseresponse relationship when attempting to supplement to achieve sufficient serum vitamin $\mathrm{D}$ concentrations (Aloia et al. 2008). The dose-response data indicates the tolerability and safety of high-dose vitamin D3 supplementation, with more rapid correction of vitamin $\mathrm{D}$ concentrations and increased likelihood of attaining optimal vitamin D concentrations seen with high doses.
Daily vitamin D intake of up to 10000 IU per day is felt to be safe, and recommendations for up to 4000 IU per day in adults have been made (Holick et al. 2011; Ross et al. 2011). In the absence of cutaneous sunlight exposure, adult males are shown to require 4000 IU per day to maintain vitamin D concentrations (Heaney et al. 2003). In a general population cohort study, vitamin D3 at $4000 \mathrm{IU} /$ day was effective in raising serum $25(\mathrm{OH}) \mathrm{D}$ to $>40 \mathrm{ng} / \mathrm{ml}$ in all adults over a duration of up to 5 months, with no safety concerns (range of vitamin D values post-supplementation $69-125 \mathrm{nmol} / \mathrm{l}$ ) (Vieth et al. 2001).

There is little data on vitamin D supplementation and dose response in schizophrenia, meaning that recommendations are based on general population data. It is pertinent that some people with schizophrenia may be unable to implement strategies to ensure adequate vitamin D levels through sunlight exposure and outdoor activity (e.g. those who are hospitalised).

In one of the few reports in mental health settings, long-term high-dose vitamin D supplementation was prescribed for the majority of admissions to a psychiatric hospital in Cincinnati, Ohio with no adverse events reported (McCullough et al. 2019). All newly admitted patients were offered 5000-10 000 IU vitamin D3 per day. Analysis of data on 36 inpatients who received $5000 \mathrm{IU} /$ day for 12 months or longer showed an increase in the mean serum $25(\mathrm{OH}) \mathrm{D}$ concentration from 24 to $68 \mathrm{ng} / \mathrm{ml}(60-170 \mathrm{nmol} / \mathrm{l})$, whereas for the 78 patients who received $10000 \mathrm{IU} /$ day, mean concentrations increased from 25 to $96 \mathrm{ng} / \mathrm{ml}$ (62.5-240 nmol/1) (McCullough et al. 2019).

Evidence from general population studies, therefore, indicates that higher doses of vitamin D supplementation may be needed (e.g. $4000 \mathrm{IU} /$ day) to treat deficiency, that such high doses are well tolerated and that the individual response may be dependent on the baseline 25(OH)D concentrations (Ross et al. 2011). 
Table 2. Risk factors for developing vitamin D deficiency

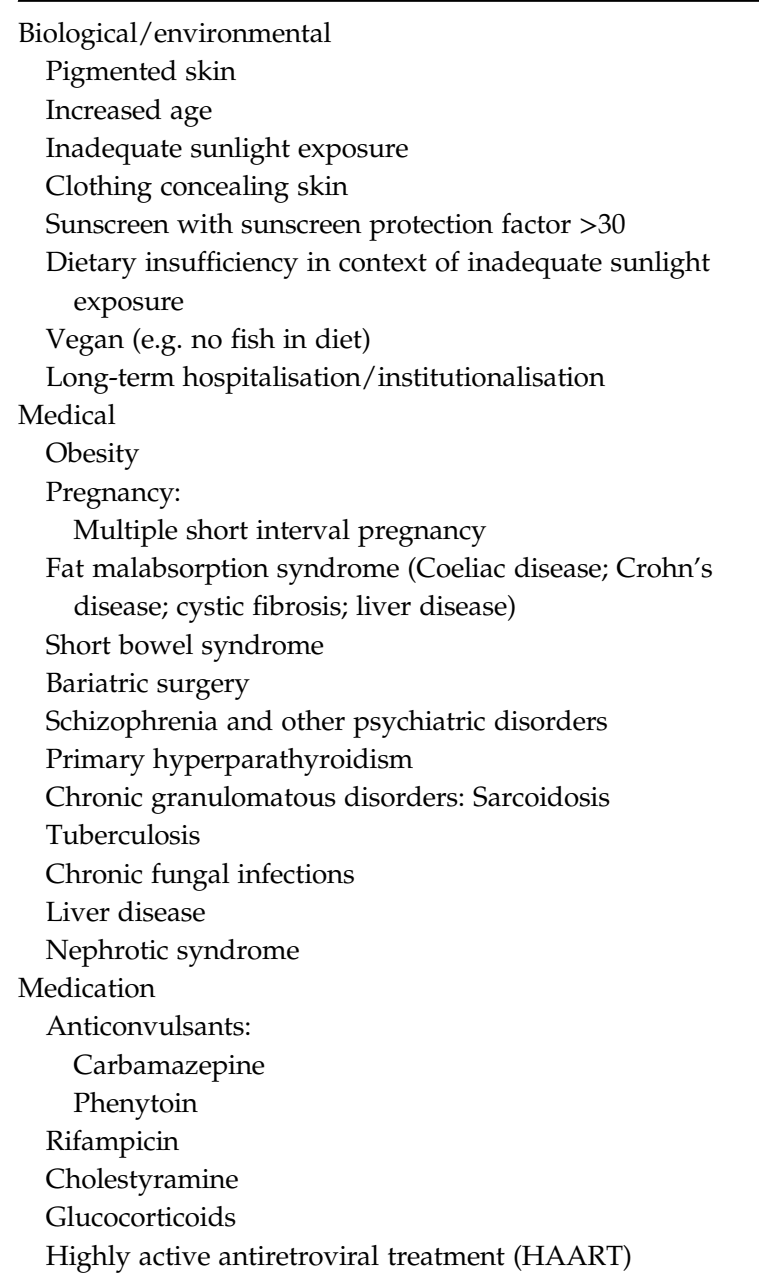

Potential benefits of vitamin $D$ supplementation in schizophrenia during the COVID-19 pandemic

People with schizophrenia have an increased prevalence of pneumonia and respiratory tract infections (Dzahini et al. 2018) with associated excess mortality, with a standardised mortality ratio (SMR) from influenza and pneumonia of 7.0 compared to the general population (Olfson et al. 2015b). Observational data shows that low serum vitamin D levels, and particularly vitamin D deficiency, are associated with a higher incidence of acute respiratory tract infections (Pham et al. 2019) and an increase in respiratory symptoms in adult populations (Mulrennan et al. 2018; Hong et al. 2020)

To date, there is no evidence of a specific effect of vitamin $\mathrm{D}$ for the treatment or prevention of COVID19 (Lee, 2020). The recommendation remains that clinicians should treat vitamin D deficiency irrespective of any link with a respiratory infection (Lee, 2020).

However, data relating to this question is emerging at pace. Preliminary reports have shown inverse correlations between serum vitamin $\mathrm{D}$ concentrations and more severe respiratory infections and mortality due to SARS-Cov2, with populations that are deficient $(<30 \mathrm{nmol} / \mathrm{l})$ being most at risk (Alipio, 2020; Ilie et al. 2020; Lau et al. 2020; Raharursan, 2020). On the other hand, an early analysis of the UK Biobank data found no association between vitamin D levels taken in 2006-2010 and subsequent infection with COVID-19 (Hastie et al. 2020).

Significant effects of vitamin D supplementation in reducing the risk of non-COVID-19 respiratory tract infections for those with lower vitamin D levels were identified in a systematic review of 7 meta-analyses of 30 RCTs (Rejnmark et al. 2017). A meta-analysis of 11 RCTs of 5389 patients found that vitamin D supplementation was associated with a $40 \%$ reduction in the risk for ARTIs (Bergman et al. 2013). Subgroup analysis found that daily administration of vitamin D3 was significantly associated with a reduction in ARTIs compared to less frequent administration, and with no effect seen for once-monthly bolus administration (Bergman et al. 2013). An RCT in 124 subjects found a significantly increased probability of remaining free from respiratory tract infections and fewer respiratory tract infections in those subjects treated with $4000 \mathrm{IU}$ vitamin D3 per day compared to a placebo-treated group (Bergman et al. 2015).

\section{Vitamin D supplementation in Schizophrenia}

There is a paucity of data on vitamin D supplementation in schizophrenia, with two RCTs investigating the effects of vitamin D3 supplementation on psychotic symptoms, cognition and cardiometabolic outcomes (Krivoy et al. 2017; Ghaderi et al. 2019), and one further RCT underway (Gaughran et al. 2020), but none investigating the effects in respiratory infections.

People with schizophrenia are more likely to have vitamin D deficiency or insufficiency (Lally et al. 2016; Adamson et al. 2017; Zhu et al. 2020). A small-cross sectional study in clozapine-treated patients identified inverse correlations between vitamin $\mathrm{D}$ concentrations and the pro-inflammatory interleukin-6 (IL-6), possibly indicative of the immunomodulatory effect of vitamin $\mathrm{D}$ in this population (Krivoy et al. 2020). However, there is insufficient evidence to stratify vitamin D supplementation, given that suboptimal vitamin D concentration is the norm in this population.

When considering vitamin D testing an initial presumptive diagnosis of insufficiency could be made, as is the case for high-risk groups in the general population, based on risk factors, without the need for (expensive) testing of vitamin D levels unless symptomatic (Lally \& Gaughran, 2019; Burton et al. 2010). Indeed, some patients with active psychosis may decline testing 
and need to be treated presumptively, taking any safety precautions into account. In the longer term, the ideal approach to vitamin D supplementation in people with schizophrenia may be ensuring prophylactic administration in line with national guidelines. However, standard recommendations for vitamin D supplementation may be inadequate to normalise vitamin $D$ levels in this group, who may be unable to implement lifestyle changes to enhance outdoor activity and vitamin D synthesis. It may, therefore, be important to take levels to assess the effect of supplementation.

Furthermore, current vitamin D treatment recommendations are to maintain vitamin $\mathrm{D}$ concentrations for the purpose of maintaining skeletal health. It is unclear, however, what the optimal levels are for protection against respiratory and viral infections. Observational data indicates that $70-90 \%$ of those with schizophrenia have vitamin D concentrations below the threshold (50 nmol/1) (Lally et al. 2016; Zhu et al. 2020) at which respiratory tract infection risk is known to increase (Pham et al. 2019).

Lifestyle advice should be offered to all patients, and education that the best source for vitamin $\mathrm{D}$ is sensible levels of sunlight exposure. Spending 10-15 minutes in the sunlight at least twice a week, with face and arms exposed, will suffice to ensure adequate vitamin D levels(Nowson et al. 2012), bearing in mind however that some psychotropic medications are associated with photosensitivity.

In treating vitamin D deficiency, the frequency of administration seems to be relevant. A meta-analysis of individual patient data identified that the protective effect of vitamin D in respiratory tract infections was significantly greater in those receiving daily or weekly doses compared to larger, less frequent bolus doses, with the effects strongest in those with vitamin D deficiency $(<25 \mathrm{nmol} / 1)$ who received daily or weekly doses (Martineau et al. 2017).

In patients with schizophrenia, most studies have shown suboptimal vitamin D levels, including in community patients. For these patients, in the absence of contraindications (see below), 4000 IU daily of vitamin D3 (with a lower dose of 2000 IU in the elderly) may be needed for a period of at least 4 weeks and up to a maximum of 12 weeks. A maintenance regimen could then be initiated guided by levels. A 4-week period of 4000 IU daily vitamin D supplementation may suffice in the Spring and Summer months in the European countries, as there remains a potential for cutaneous vitamin D synthesis in the Summer months. A longer period of supplementation may be more appropriate in the Autumn and Winter months (up to 12 weeks). These recommendations may be more relevant to inpatients and those in long-term care residential facilities, settings in which increased morbidity and mortality secondary to the level of COVID-19 have been identified.

In adults with vitamin D deficiency, vitamin D3 supplementation will not lead to a normalising of $25(\mathrm{OH}) \mathrm{D}$ concentrations until an 8-12-week period of adequate dosing is complete, so vitamin D levels should not be checked for at least 12 weeks after treatment initiation. It is appropriate to check baseline serum calcium and at 4 weeks to assess for hypercalcaemia and an unmasked primary hyperparathyroidism.

Caution or referral for specialist opinion is recommended if there is evidence or a history of hypercalcaemia, a history of granulomatous disorders (Sarcoidosis, tuberculosis), a history of lymphoma, a history of renal calculi or renal impairment with eGFR $<60 \mathrm{ml} / \mathrm{min}$. Nephrology advice is recommended for those with renal impairment, as 1,25-dihydroxyvitamin D may be required.

\section{Vitamin D toxicity}

While rare, vitamin D toxicity can cause severe hypercalcaemia when ingested at excessive amounts over a long period of time (Heaney et al. 2003). Serum $25(\mathrm{OH}) \mathrm{D}$ concentrations would need to exceed $150 \mathrm{ng} / \mathrm{ml}$ $(375 \mathrm{nmol} / \mathrm{l})$ before toxicity may become an issue, and the risk of hypercalcaemia is mitigated by ensuring vitamin $\mathrm{D}$ levels remain below $100 \mathrm{ng} / \mathrm{ml}$ (250 nmol/1) (Holick et al. 2011). Cohort studies have shown that dosing up to $40000 \mathrm{IU}$ per day over 28 weeks did not cause an increase in adverse effects, and supplementation at $5500 \mathrm{IU}$ for 20 weeks did not raise serum concentrations above $160 \mathrm{nmol} / 1$ (Holick et al. 2011). The risk for vitamin D-induced hypercalcaemia is low, with rates of transient mild hypercalcaemia $(2.56-2.64 \mathrm{mmol} / \mathrm{l})$ of $3 \%$ and no severe hypercalcaemia in a population of healthy adults aged 55-70 treated with $4000 \mathrm{IU} /$ day for 3 years (Billington et al. 2019).

\section{Conclusion}

With the advent of a new respiratory pandemic, SARSCov2, that as of yet does not show consistent response to antiviral therapy and with no vaccine immediately available, it is important to optimise the underlying health state of patients with schizophrenia. The importance of this question in people with schizophrenia is amplified by their increased likelihood of exposure to infection in hospital settings and the high rates of COVID-19-relevant co-morbidities. Further evidence is urgently needed regarding the effectiveness of vitamin $\mathrm{D}$ optimisation as a protective measure in this group.

This review presents the evidence that optimisation of vitamin $\mathrm{D}$ could be beneficial to those with 
schizophrenia and other psychotic disorders through possible protective effects against respiratory tract infections. While specific optimisation strategies have not been devised for those with schizophrenia, it is reasonable to adapt the general population guidelines, bearing in mind the greatly enhanced likelihood of vitamin D deficiency in those with psychotic disorders.

The prophylactic use of vitamin D supplementation to at-risk groups such as patients with schizophrenia may prove to be a cost-effective measure to improve resilience to respiratory infections. It is possible that this effect may extend to SARS-Cov2 infection, although clinical trial evidence supporting this is not yet available.

\section{Conflict of interest}

FG declares a potential conflict of interest, although not in relation to this work. The other authors (DVW, SKW, DT, JL) declares no conflict of interest.

\section{Ethical standards}

The authors (DVW, SKW, DT, FG, JL) assert that all procedures contributing to this work comply with the ethical standards of the relevant national and institutional committee on human experimentation with the Helsinki Declaration of 1975, as revised in 2008.

\section{Funding}

FG has received support or honoraria for CME, advisory work and lectures from Lundbeck, Otsuka and Sunovion, collaborated on research funded by an NHS Innovations/Janssen-Cilag award and has a family member with professional links to Lilly and GSK, including shares. FG is in part, funded by the National Institute for Health Research Collaboration for Leadership in Applied Health Research and Care Funding scheme and the NIHR Biomedical Research Centre at South London and Maudsley NHS Foundation Trust and King's College London. The views expressed in this publication are those of the authors and not necessarily those of the NHS, the NIHR or the Department of Health. The other authors have no financial relationships with any organisations that might have an interest in the submitted work in the previous 3 years; there are no other relationships or activities that could appear to have influenced the submitted work.

\section{References}

Adamson J, Lally J, Gaughran F, Krivoy A, Allen L, Stubbs B (2017). Correlates of vitamin D in psychotic disorders: a comprehensive systematic review. Psychiatry Research 249, 78-85.
Alipio MM (2020). LETTER-PREPRINT Vitamin D supplementation could possibly improve clinical outcomes of patients infected with Coronavirus-2019 (Covid-2019). (https://ssrn.com/abstract=3571484). Accessed May 15, 2020.

Aloia JF, Patel M, DiMaano R, Li-Ng M, Talwar S, Mikhail M, Pollack S, Yeh J (2008). Vitamin D intake to attain a desired serum 25-hydroxyvitamin D concentration. The American Journal of Clinical Nutrition 87, 1952-1958.

Bergman P, Lindh A, Björkhem-Bergman L, Lindh J (2013). Vitamin D and respiratory tract infections: a systematic review and meta-analysis of randomized controlled trials. PLOS ONE 8, e65835.

Bergman P, Norlin A, Hansen S, Björkhem-Bergman L (2015). Vitamin D supplementation to patients with frequent respiratory tract infections: a post hoc analysis of a randomized and placebo-controlled trial. BMC Research Notes 8. doi: 10.1186/s13104-015-1378-3.

Billington EO, Burt L, Rose M, Davison E, Gaudet S, Kan M, Boyd S, Hanley D. (2019). Safety of high-dose vitamin D supplementation: secondary analysis of a randomized controlled trial. The Journal of Clinical Endocrinology \& Metabolism, 105, 1261-1273.

Bolland M, Grey A, Avenell A (2018). Effects of vitamin D supplementation on musculoskeletal health: a systematic review, meta-analysis, and trial sequential analysis. The Lancet Diabetes \& Endocrinology 6. doi: 10.1016/S22138587(18)30265-1.

Bouillon R, Marcocci C, Carmeliet G, Bikle D, White JH, Dawson-Hughes B, Lips P, Munns CF, Lazaretti-Castro M, Giustina A, Bilezikian J (2019). Skeletal and extraskeletal actions of vitamin D: current eidence and outstanding questions. Endocrine Reviews: The Endocrine Society 40, 1109-1151.

Burton JM, Kimball S, Vieth R, Bar-Or, Dosch HM, Cheung R, Gagne D, D'Souza C, Ursell M, O'Connor P (2010). A phase I/II dose-escalation trial of vitamin D3 and calcium in multiple sclerosis. Neurology 74, 1852-1859.

Cao X (2020). COVID-19: immunopathology and its implications for therapy. Nature Reviews Immunology: Nature Research 269-270. doi: 10.1038/s41577-020-0308-3.

Chen N, Wan Z, Han S, Li B, Zhang Z, Qin L (2014). Effect of vitamin D supplementation on the level of circulating high-sensitivity C-reactive protein: a metaanalysis of randomized controlled trials. Nutrients $\mathbf{6}$, 2206-2216.

Chun RF, Liu P, Modlin R, Adams J, Hewison M (2014). Impact of vitamin $\mathrm{D}$ on immune function: lessons learned from genome-wide analysis. Frontiers in Physiology 5, 151.

Crews M, Lally J, Gardner-Sood P, Howes O, Bonaccorso S, Smith S, Murray R, Di Forti M, Gaughran F (2013). Vitamin D deficiency in first episode psychosis: a casecontrol study. Schizophrenia Research 150, 533-537.

Dawson-Hughes B, Mithal A, Bonjour J-P, Boonen S, Burckhardt P, Burckhardt GE-H, Josse RG, Lips P, Morales-Torres J, Yoshimura N (2010). IOF position statement: vitamin D recommendations for older adults. 
Osteoporos Int 21, 1151-1154. doi: 10.1007/s00198-0101285-3

Dzahini O, Singh N, Taylor D, Haddad P (2018). Antipsychotic drug use and pneumonia: systematic review and meta-analysis. Journal of Psychopharmacology 32, 1167-1181.

Food Safety Authority of Ireland (2011). Scientific Recommendations for Healthy Eating Guidelines in Ireland. Food Safety Authority of Ireland: Ireland.

Gardner-Sood P, Lally J, Smith S, Atakan Z, Ismail K, Greenwood K, Keen A, O'Brien C, Onagbesan O, Fung C, Papanastasiou E, Eberherd J, Patel A, Ohlsen R, Stahl D, David A, Hopkins D, Murray R, Gaughran F (2015). Cardiovascular risk factors and metabolic syndrome in people with established psychotic illnesses: baseline data from the IMPaCT randomized controlled trial. Psychological Medicine 45, 2619-2629.

Gaughran F, Stahl D, Stringer D, Hopkins D, Atakan Z, Greenwood K, Patel A, Smith S, Gardner-Sood P, Lally J, Heslin M, Stubbs B, Bonaccorso S, Kolliakou A, Howes O, Taylor D, Forti M, David A, Murray R, Ismail K (2019). Effect of lifestyle, medication and ethnicity on cardiometabolic risk in the year following the first episode of psychosis: prospective cohort study. British Journal of Psychiatry 215, 712-719.

Gaughran F, Stringer D, Berk M, Smith S, Taylor D, Whiskey E, Landau S, Murray R, McGuire P, GardnerSood P, Wojewodka G, Ciufolni S, Jordan H, Clarke J, Allen, L, Krivoy A, Stubbs B, Lowe P, Arbuthnott M, Rathod S, Boardman A, Firdosi M, McGrath J (2020). Vitamin D supplementation compared to placebo in people with First Episode psychosis: neuroprotection design (DFEND): a protocol for a randomised, doubleblind, placebo-controlled, parallel-group trial. Trials 21, 14 .

Ghaderi A, Banafshe H, Mirhosseini N, Moradi M, Karimi M, Mehrzad F, Bahmani F, Asemi Z (2019). Clinical and metabolic response to vitamin D plus probiotic in schizophrenia patients. BMC Psychiatry $19,77$.

Ghavideldarestani M, Honardoost M, Khamseh ME (2020). Role of vitamin $\mathrm{D}$ in pathogenesis and severity of COVID-19 infection Role of vitamin D in pathogenesis and severity of COVID-19 infection. Preprints 2-17. doi: 10.20944/preprints202004.0355.v1.

Grant WB (2008). Variations in vitamin D production could possibly explain the seasonality of childhood respiratory infections in Hawaii. The Pediatric Infectious Disease Journal 27, 853.

Grant WB, Lohare H, McDonnell S, Baggerly C, French C, Alianoj, Bhattoa H (2020). Evidence that vitamin d supplementation could reduce risk of influenza and covid-19 infections and deaths. Nutrients. doi: 10.3390/ nu12040988.

Grant WB, Giovannucci E (2009). The possible roles of solar ultraviolet-B radiation and vitamin $\mathrm{D}$ in reducing casefatality rates from the 1918-1919 influenza pandemic in the United States. Dermato-Endocrinology 1, 215-219.
Gruber-Bzura BM (2018). Vitamin D and influenzaprevention or therapy? International Journal of Molecular Sciences 19, 2419.

Hastie CE, Mackay D, Ho F, Celis-Morales C, Katikireddi S, Niedzwiedz C, Jani B, Welsh P, Mair F, Gray S, O'Donnell C, Sattar N, Pell J (2020). Vitamin D concentrations and COVID-19 infection in UK Biobank. Diabetes and Metabolic Syndrome: Clinical Research and Reviews 14, 561-565.

Heaney RP, Davies K, Chen T, Holick M, Barger-Lux M (2003). Human serum 25-hydroxycholecalciferol response to extended oral dosing with cholecalciferol. The American Journal of Clinical Nutrition 77, 204-210.

Hjorthøj C, Stürup A, McGrath J, Nordentoft M (2017). Years of potential life lost and life expectancy in schizophrenia: a systematic review and meta-analysis. The Lancet Psychiatry 4, 295-301.

Holick MF (2006). High prevalence of vitamin D inadequacy and implications for health. Mayo Clinic Proceedings 353-373. doi: 10.4065/81.3.353.

Holick MF, Chen TC (2008). Vitamin D deficiency: a worldwide problem with health consequences. American Journal of Clinical Nutrition 87, 1080-1086. doi: 10.1093/ ajcn/87.4.1080S

Holick MF, Binkley N, Bischoff-Ferrari H, Gordon C, Hanley D, Heaney R, Murad M, Weaver C (2011). Evaluation, treatment, and prevention of vitamin D deficiency: an endocrine society clinical practice guideline. Journal of Clinical Endocrinology and Metabolism 1911-1930. doi: 10.1210/jc.2011-0385.

Holick MF (2012). Vitamin D: physiology, dietary sources, and requirements. In Encyclopedia of Human Nutrition, pp. 370-382. Elsevier Inc. doi: 10.1016/B978-0-12-3750839.00276-2.

Hong $\mathrm{M}$, Xiong $\mathrm{T}$, Huang J, Wu Y, Lin L, Zhang Z, Huang L, Gao D, Wang H, Kang C, Gao Q, Yang X, Yang N, Hao L (2020). Association of vitamin D supplementation with respiratory tract infection in infants. Maternal \& Child Nutrition. doi: 10.1111/mcn.12987.

Huang F, Zhang C, Liu Q, Zhao Y, Zhang Y, Qin Y, Li X, Li C, Zhou C, Jin N, Jiang C (2020). Identification of amitriptyline $\mathrm{HCl}$, flavin adenine dinucleotide, azacitidine and calcitriol as repurposing drugs for influenza A H5N1 virus-induced lung injury. PLOS Pathogens 16, e1008341.

Ilie PC, Stefanescu S, Smith L (2020). The role of vitamin D in the prevention of coronavirus disease 2019 infection and mortality. Aging Clinical and Experimental Research. doi: 10.1007/s40520-020-01570-8.

Komolmit P, Charoensuk K, Thanapirom K, Suksawatamnuay $S$, Thaimai $P$, Chirathaworn $C$, Poovorawan Y (2017). Correction of vitamin D deficiency facilitated suppression of IP-10 and DPP IV levels in patients with chronic hepatitis C: a randomised doubleblinded, placebo-control trial. PLOS ONE 12. doi: 10.1371/ journal.pone.0174608.

Kozloff N, Mulsant B, Stergiopoulos V, Voineskos A (2020). The COVID-19 global pandemic: implications for 
people with schizophrenia and related disorders. Schizophrenia Bulletin. doi: 10.1093/schbul/sbaa051.

Krivoy A, Onn R, Vilner Y, Hochman E, Weizman S, Paz, Hess S, Sagy R, Kimhi-Nesher S, Kalter E, Friedman T, Friedman Z, Bormant G, Trommer S, Valevski A, Weizman A (2017). Vitamin D supplementation in chronic schizophrenia patients treated with clozapine: a randomized, double-blind, placebo-controlled clinical trial. EBioMedicine 26, 138-145.

Krivoy A, Satz J, Hornfeld S, Bar L, Gaughran F, Shoval G, Hochman E, Weizman A, Taler M (2020). Low levels of serum vitamin $\mathrm{D}$ in clozapine-treated schizophrenia patients are associated with high levels of the proinflammatory cytokine IL-6. International Clinical Psychopharmacology 35, 208-213.

Laird E, Anne Kenny R (2020). Vitamin D deficiency in Ireland-implications for COVID-19: results from the Irish Longitudinal Study on Ageing (TILDA). doi: 10.38018/ TildaRe.2020-05.

Lally J, Gardner-Sood P, Firdosi M, Lyegbe C, Stubbs B, Greenwood K, Murray R, Smith S, Howes O, Gaughran F (2016). Clinical correlates of vitamin D deficiency in established psychosis. BMC Psychiatry 16, 76.

Lally J, Spaducci G, Gardner-Sood P, Atakan Z, Greenwood K, Di Forti M, Ismail K, Murphy KC, Smith S, McNeill A, Murray RM, Gaughran F (2019). Tobacco smoking and nicotine dependence in first episode and established psychosis. Asian Journal of Psychiatry 43, 125-131.

Lally J, Ajnakina O, Singh N, Gardner-Sood P, Stubbs B, Strinegr D, Di Forti M, David A, Smith S, Murray R, Howes O, Gaughran F (2019). Vitamin D and clinical symptoms in First Episode Psychosis (FEP): a prospective cohort study. Schizophrenia Research 204, 381-388.

Lally J, Gaughran F (2019). Vitamin D in schizophrenia and depression: a clinical review. BJPsych Advances 25, 240-248.

Lang PO, Samaras N, Samaras D, Aspinall R (2013). How important is vitamin $\mathrm{D}$ in preventing infections?. Osteoporosis International 24, 1537-1553.

Lang PO, Aspinall R (2017). Vitamin D status and the host resistance to infections: what it is currently (Not) understood. Clinical Therapeutics 39, 930-945.

Lau FH, Majumder R, Torabi R, Saeg F, Hoffman R, Cirillo J, Greiffenstein P (2020). Vitamin D insufficiency is prevalent in severe COVID-19. medRxiv p. 20075838. doi: $10.1101 / 2020.04 .24 .20075838$.

Lee J, van Hecke O, Roberts N (2020). Vitamin D: a rapid review of the evidence for treatment or prevention in COVID-19: CEBM. https://www.cebm.net/covid-19/ vitamin-d-a-rapid-review-of-the-evidence-for-treatmentor-prevention-in-covid-19/). Accessed May 162020.

Lu R, Zhao X, Li J, Niu P, Yang B, Wu H (2020). Genomic characterisation and epidemiology of 2019 novel coronavirus: implications for virus origins and receptor binding. The Lancet 395, 565-574.

Martineau AR, Jolliffe DA, Hooper RL, Greenberg L, Aloia JF, Bergman P, Dubnov-Raz G, Esposito S, Ganmaa D, Ginde AA, Goodall EC, Grant CC,
Griffiths CJ, Janssens W, Laaksi I, Manaseki-Holland S, Mauger D, Murdoch DR, Neale R, Rees JR, Simpson S, Stelmach I, Kumar GT, Uramashima M, Camargo CA (2017). Vitamin D supplementation to prevent acute respiratory tract infections: systematic review and metaanalysis of individual participant data. BMJ 356, i6583. doi: $10.1136 /$ bmj.i6583.

Martineau AR, Jolliffe D, Greenberg L, Aloia J, Bergman P, Dubnov-Raz G, Esposito S, Ganmaa D, Ginde A, Goodall E, Grant C, Janssens W, Jensen M, Kerley C, Laaski I, Manaseki-Holland S, Mauger D, Murdoch D, Neale R, Rees J, Simpson S, Stelmach I, Trilok Kumar G, Urashima M, Camargo C, Griffiths C, Hooper R (2019). Vitamin D supplementation to prevent acute respiratory infections: individual participant data meta-analysis. Health Technology Assessment 23, 1-44.

Mccartney DM, Byrne DG (2020). Optimisation of vitamin D status for enhanced immuno-protection against covid19. The Irish Medical Journal 113, 58.

McCullough PJ, Lehrer DS, Amend J (2019). Daily oral dosing of vitamin D3 using 5000 TO 50,000 international units a day in long-term hospitalized patients: Insights from a seven year experience. Journal of Steroid Biochemistry and Molecular Biology 189, 228-239.

Mulrennan S, Knuiman M, Walsh, JP, Hui J, Hunter M, Divitini M, Zhu K, Cooke BR, Musk AWB, James A (2018). Vitamin D and respiratory health in the Busselton Healthy Ageing Study. Respirology 23, 576-582.

Nowson CA, McGrath JJ, Ebeling PR, Halikerwal A, Daly RM, Sanders KM, Seibel MJ, Mason RS (2012). Vitamin $\mathrm{D}$ and health in adults in Australia and New Zealand: a position statement. Medical Journal of Australia 196, 686-687.

Olfson M, Gerhard T, Huang C, Crystal S, Stroup TS (2015a). Premature mortality among adults with schizophrenia in the United States. JAMA Psychiatry 72, 1172-1181.

Olfson M, Gerhard T, Huang C, Crystal S, Stroup TS (2015b). Premature mortality among adults with schizophrenia in the United States. JAMA Psychiatry 72, 1172-1181.

Patel D, Minajagi M (2018). Prevalence of vitamin D deficiency in adult patients admitted to a psychiatric hospital. BJPsych Bulletin 42, 123-126.

Pham H, Rahnam A, Majidi A, Waterhouse M, Neale RE (2019). Acute respiratory tract infection and 25hydroxyvitamin D concentration: a systematic review and meta-analysis. International Journal of Environmental Research and Public Health 16, 3020.

Raharursan P (2020). Patterns of COVID-19 mortality and vitamin D: an Indonesian study. papers.ssrn.com ( ...https://papers.ssrn.com/sol3/papers .... act_id=3585561). Accessed May 152020.

Redzic M, Lewis RM, Thomas DT (2013). Relationship between 25-hydoxyvitamin D, muscle strength, and incidence of injury in healthy adults: a systematic review. Nutrition Research 251-258. doi: 10.1016/j.nutres. 2013.02.007. 
Rejnmark L, Bislev LS, Cashman KD, Eiríksdottir G, Gaksch M, Grübler M, Grimnes G, Gudnason V, Lips P, Pilz S, Van Schoor NM, Kiely M, Jorde R (2017). Non-skeletal health effects of Vitamin D supplementation: A systematic review on findings from meta-Analyses summarizing trial data. PLOS ONE p. e0180512. doi: 10.1371/journal.pone.0180512.

Rhodes JM, Subramanian S, Laird E, Anne Kenny R (2020). Editorial: low population mortality from COVID19 in countries south of latitude 35 degrees North: supports vitamin $\mathrm{D}$ as a factor determining severity. . doi: 10.1111/apt.15777.

Ross AC, Manson JE, Abrams SA, Aloia JF, Brannon PM, Clinton SK, Durazo-Arvizu RA, Gallagher JC, Gallo RL, Jones G, Kovacs CS, Mayne ST, Rosen CJ, Shapses SA (2011). The 2011 report on dietary reference intakes for calcium and vitamin D from the institute of medicine: what clinicians need to know. The Journal of Clinical Endocrinology \& Metabolism 96, 53-58.

Ruston D, Hoare J, Henderson L, Gregory J, Bates CJ, Prentice A (2004). The National Diet \& Nutrition Survey: Adults Aged 19 to 64 Years: Nutritional Status (Anthropometry and Blood Analytes), Blood Pressure and Physical Activity. TSO: London.

Vieth R, Chan PR, MacFarlane GD (2001). Efficacy and safety of vitamin D3 intake exceeding the lowest observed adverse effect level. The American Journal of Clinical Nutrition 73, 288-294.

Walls AC, Park YJ, Tortorici MA, Wall A, McGuire A, Veesler D (2020). Structure, function, and antigenicity of the SARS-CoV-2 spike glycoprotein. Cell 181, 281-292.e6.

Wu Z, McGoogan JM (2020). Characteristics of and important lessons from the coronavirus disease 2019 (COVID-19) outbreak in China: summary of a report of 72 314 cases from the Chinese center for disease control and prevention. JAMA 323, 1239-1242.

Xu J, Yang J, Chen J, Luo Q, Zhang $Q$, Zhang $H$ (2017). Vitamin D alleviates lipopolysaccharideinduced acute lung injury via regulation of the renin-angiotensin system. Molecular Medicine Reports 16, 7432-7438.

Zhou YF, Zhou Ruzhen, Zhang Z, Li K (2019). The association between vitamin $\mathrm{D}$ deficiency and community-acquired pneumonia: a meta-analysis of observational studies. Medicine (United States) 98. doi: 10. 1097/MD.0000000000017252.

Zhu J, Luo W, Cheng X, Li Y, Zhang Q, Peng W (2020). Vitamin D deficiency and Schizophrenia in adults: a systematic review and meta-analysis of observational studies. Psychiatry Research p. 112959. doi: 10.1016/j.psychres.2020.112959. 